\title{
New Neuroprotective Effect of Lemon IntegroPectin on Neuronal Cellular Model
}

\author{
Domenico Nuzzo ${ }^{1,2, *(\mathbb{D})}$, Pasquale Picone ${ }^{1,2}$, Costanza Giardina ${ }^{3}$, Miriana Scordino ${ }^{3}$, Giuseppa Mudò ${ }^{3}$, \\ Mario Pagliaro ${ }^{4}$ (D), Antonino Scurria ${ }^{4}$ (D), Francesco Meneguzzo ${ }^{5}$ (D), Laura M. Ilharco ${ }^{6}$, Alexandra Fidalgo ${ }^{6}$, \\ Rosa Alduina $^{2}\left(\mathbb{D}\right.$, Alessandro Presentato ${ }^{2} \mathbb{D}$, Rosaria Ciriminna ${ }^{4, *} \mathbb{D}$ and Valentina Di Liberto ${ }^{3, *}$
}

1 Istituto per la Ricerca e l'Innovazione Biomedica, CNR, via U. La Malfa 153, 90146 Palermo, Italy; pasquale.picone@irib.cnr.it

2 Dipartimento di Scienze e Tecnologie Biologiche Chimiche e Farmaceutiche, Università di Palermo, Viale delle Scienze, 90128 Palermo, Italy; valeria.alduina@unipa.it (R.A.); alessandro.presentato@unipa.it (A.P.)

3 Dipartimento di Biomedicina, Neuroscienze e Diagnostica Avanzata, Università di Palermo, Corso Tukory 129, 90134 Palermo, Italy; costanza.giardina@unipa.it (C.G.); miriana.scordino@you.unipa.it (M.S.); giuseppa.mudo@unipa.it (G.M.)

4 Istituto per lo Studio dei Materiali Nanostrutturati, CNR, via U. La Malfa 153, 90146 Palermo, Italy; mario.pagliaro@cnr.it (M.P.); antonino.scurria@ismn.cnr.it (A.S.)

5 Istituto per la Bioeconomia, CNR, via Madonna del Piano 10, 50019 Sesto Fiorentino, Italy; francesco.meneguzzo@cnr.it

6 Centro de Química-Física Molecular and IN-Institute of Nanoscience and Nanotechnology, Instituto Superior Técnico, Universidade de Lisboa, Av. Rovisco Pais 1, 1049-001 Lisboa, Portugal; lilharco@tecnico.ulisboa.pt (L.M.I.); alexandra.fidalgo@ist.utl.pt (A.F.)

check for updates

Citation: Nuzzo, D.; Picone, P.; Giardina, C.; Scordino, M.; Mudò, G.; Pagliaro, M.; Scurria, A.; Meneguzzo, F.; Ilharco, L.M.; Fidalgo, A.; et al. New Neuroprotective Effect of Lemon IntegroPectin on Neuronal Cellular Model. Antioxidants 2021, 10, 669. https://doi.org/10.3390/ antiox10050669

Academic Editor: Laszlo Tretter

Received: 26 March 2021

Accepted: 22 April 2021

Published: 25 April 2021

Publisher's Note: MDPI stays neutral with regard to jurisdictional claims in published maps and institutional affiliations.

Copyright: (c) 2021 by the authors. Licensee MDPI, Basel, Switzerland. This article is an open access article distributed under the terms and conditions of the Creative Commons Attribution (CC BY) license (https:/ / creativecommons.org/licenses/by/ $4.0 /)$.
* Correspondence: domenico.nuzzo@cnr.it (D.N.); rosaria.ciriminna@cnr.it (R.C.); valentina.diliberto@unipa.it (V.D.L.)

\begin{abstract}
Lemon IntegroPectin obtained via hydrodynamic cavitation of organic lemon processing waste in water shows significant neuroprotective activity in vitro, as first reported in this study investigating the effects of both lemon IntegroPectin and commercial citrus pectin on cell viability, cell morphology, reactive oxygen species (ROS) production, and mitochondria perturbation induced by treatment of neuronal SH-SY5Y human cells with $\mathrm{H}_{2} \mathrm{O}_{2}$. Mediated by ROS, including $\mathrm{H}_{2} \mathrm{O}_{2}$ and its derivatives, oxidative stress alters numerous cellular processes, such as mitochondrial regulation and cell signaling, propagating cellular injury that leads to incurable neurodegenerative diseases. These results, and the absence of toxicity of this new pectic substance rich in adsorbed flavonoids and terpenes, suggest further studies to investigate its activity in preventing, retarding, or even curing neurological diseases.
\end{abstract}

Keywords: pectin; hesperidin; flavonoids; neurological disease; antioxidant; oxidative stress; neuroprotective; mitochondria

\section{Introduction}

Recently called by Russian scholars a "universal medicine" [1], pectin is also the most valued and versatile natural hydrocolloid used by the industry [2]. Research on the broad scope biological activity of this heterogeneous, galacturonic acid-rich polysaccharide ubiquitous in plant cell walls where it acts as a cellular adhesive [3], is flourishing [1]. Its antibacterial properties, for example, have been lately rediscovered [4]. Lowering blood sugar levels and improving blood-sugar-related hormone function [5,6], the consumption of pectin also reduces serum cholesterol by binding with cholesterol in the digestive tract [7].

Neurological disorders (ND) such as Alzheimer's and Parkinson's disease, and amyotrophic lateral sclerosis, causing the progressive death of the neurons, are a major cause of death and disability worldwide [8]. The occurrence of these morbidities has increased dramatically in recent years due to the ageing of the population in industrially developed 
countries, various forms of environmental pollution [9], lifestyle, nutrition (e.g., lack of sufficient intake of omega-3 essential lipids) [10,11], virus infections, and other environmental and social factors [12]. The number of patients needing neurological treatment is expected to continue to grow in the coming decades [8], along with the related healtcare costs.

Oxidative stress, one of the major mechanisms involved in ND, alters numerous cellular processes such as mitochondrial regulation [13], DNA repair, and cell signaling being propagating cellular injury that leads to incurable neurodegenerative diseases [14,15].

In 2012, Chinese scholars first reported that ginseng pectin protects neuronal cell lines from hydrogen peroxide-induced toxicity, attenuating $\mathrm{H}_{2} \mathrm{O}_{2}$-induced damage up to $26 \%$ in primary cortical neuron cells and human glioblastoma cells, maintaining cell integrity and decreasing nuclei condensation [16]. In brief, ginseng pectin acts as a neurotrophin, protecting neurite integrity. The team concluded that ginseng pectin might serve "as a potential therapeutic agent for neurodegenerative diseases" [16]. Unfortunately, in analogy with what happened with the 1970 reports of broad scope antibacterial activity of citrus pectins [4], no subsequent report on neuroprotective action of this and other pectins was described in the following decade.

From alkaloid securinine obtained from the root of Securinega suffruticosa [17] through citrus flavonoids [18], natural products of high antioxidant potency are increasingly investigated as neuroprotective agents for the prevention, retard, or reverse of neurodegenerative diseases [19]. For instance, the neuroprotective mechanism of flavonoids, is thought to proceed via multiple mechanisms including suppression of lipid peroxidation, inhibition of inflammatory mediators, modulation of gene expressions and improvement of the activity of antioxidant enzymes [18]. Combined with regular physical exercise [20], increasing the intake of fruits containing bioactive antioxidants is suggested to delay or inhibit neurodegeneration and correlated diseases [21].

In this context, the discovery of a new citrus pectin derived via hydrodynamic cavitation of citrus processing waste (the industrial residue of citrus juice extraction) carried out directly on a semi-industrial scale was reported in late 2019 [22]. Called "IntegroPectin", this pectic polymer largely differs from traditional citrus pectin extracted from dried citrus peel via acidic hydrolysis in hot water. Containing large amounts of flavonoids and terpenes, lemon and grapefruit IntegroPectin, for instance, are broad scope bactericidal agents showing vastly enhanced antimicrobial activity when compared to commercial citrus pectin [23]. Lemon IntegroPectin is also a powerful radical scavenger, with an ORAC (Oxygen Radical Absorbance Capacity) value of 122,200 $\mu \mathrm{mol} \mathrm{TE} / 100 \mathrm{~g}$ (compared to $16,210 \mu \mathrm{mol} \mathrm{TE} / 100 \mathrm{~g}$ of black rapsberry fruit) and significant cytoprotective activity when tested with human epithelial cells [24]. Now, we report that lemon (Citrus limon) IntegroPectin exerts significant neuroprotective activity in vitro against $\mathrm{H}_{2} \mathrm{O}_{2}$-induced damage of neuronal cells, with neuroprotection likely occurring through protection of mitochondria.

\section{Materials and Methods}

\subsection{Solubilization of Pectin}

Commercial pectin derived from citrus peels (galacturonic acid, $\geq 74.0 \%$, dried basis, Sigma-Aldrich, Merck, Darmstadt, Germany), labelled "Citrus" in Figures, and lemon IntegroPectin obtained as previously described [24] (labelled "Lemon" in Figures), were solubilized dissolving $1 \mathrm{mg}$ of pectic polymer powder in $10 \mathrm{~mL}$ of Phosphate Buffer Saline (PBS, $\mathrm{pH}=7.4,137 \mathrm{mM} \mathrm{NaCl}, 2.7 \mathrm{mM} \mathrm{KCl}, 8 \mathrm{mM} \mathrm{Na}_{3} \mathrm{PO}_{4}$ ). The supernatant was collected, filtered using a $0.45 \mu \mathrm{m}$ sartorius filter, aliquoted $(1 \mathrm{~mL} / \mathrm{vial})$, and stored at $+4{ }^{\circ} \mathrm{C}$.

\subsection{Cell Cultures and Treatment}

SH-SY5Y cells generously provided by Professor Venera Cardile, University of Catania, Italy, were cultured in T25 tissue culture flasks. Complete Dulbecco's Modified Eagle's Medium and F12 (DMEM/F12; 1:1) was used, supplemented with 10\% fetal bovine serum (FBS), $100 \mathrm{U} / \mathrm{mL}$ penicillin and $100 \mathrm{U} / \mathrm{mL}$ streptomycin and $2 \mathrm{mM}$ L-Glutamine in a humidified atmosphere of $95 \%$ air and $5 \% \mathrm{CO}_{2}$ at $37^{\circ} \mathrm{C}$. The cell culture medium was 
every three days, and the cells were sub-cultured once they reached $90 \%$ confluence. The effects of pectins in solution on all the analyzed parameters were tested in cells cultured for $72 \mathrm{~h}$ in 96 -wells plates. All treatments were performed at least $24 \mathrm{~h}$ after plating. Based on the experimental groups, the cells received the following treatments: $\mathrm{H}_{2} \mathrm{O}_{2}(200 \mu \mathrm{M}$ for $24 \mathrm{~h}$ ), dissolved pectins (Citrus or Lemon, $1 \mathrm{mg} / \mathrm{mL}, 0.1 \mathrm{mg} / \mathrm{mL}$ and $0.01 \mathrm{mg} / \mathrm{mL}$ for $24 \mathrm{~h}$ or $48 \mathrm{~h}$ ), a combination of pectins and $\mathrm{H}_{2} \mathrm{O}_{2}$, with pectins administered $24 \mathrm{~h}$ before (pretreatment), immediately before (co-treatment), or $3 \mathrm{~h}$ after $\mathrm{H}_{2} \mathrm{O}_{2}$ exposure (treatment). The control (Ctrl) groups received only an equal volume of the solvent medium.

\subsection{Cell Viability and Cell Morphology}

Cells were grown at a density of $2 \times 10^{4}$ cell/well on 96-well plates in a final volume of $100 \mu \mathrm{L} /$ well. Cell viability was assessed by measuring the amount of coloured formazan by the reduction of 3-(4,5-dimethylthiazol-2-yl)-2,5-diphenyltetrazolium bromide (MTT, $0.5 \mathrm{mg} / \mathrm{mL}$ ) by viable cells after $3 \mathrm{~h}$ incubation at $37^{\circ} \mathrm{C}$. Absorbance was measured at $570 \mathrm{~nm}$ with background subtraction after dissolving formazan crystals with dimethyl sulfoxide (DMSO) $100 \mu \mathrm{L} /$ well. Cell viability was expressed as arbitrary units, with the control group set to 1 . For analysis of cell morphology, cells were grown at a density of $5 \times 10^{3}$ cell/well on 96-well plates in a final volume of $100 \mu \mathrm{L} /$ well. At the end of the experiments, the cells were fixed with $4 \%$ formaldehyde solution for $15 \mathrm{~min}$ at room temperature, washed twice with PBS, and nuclei were counterstained with the fluorescent stain 4',6-diamidino-2-phenylindole (DAPI). The cellular images obtained using the Zeiss Axio Scope 2 microscope (Carl Zeiss, Oberkochen, Germany) were analyzed with the ZEISS-ZEN imaging software, measuring each time the cell body size and the number of cell debris per field.

\subsection{Analysis of Reactive Oxygen Species (ROS)}

To assess ROS generation, SH-SY5Y cells were placed at a density of $1 \times 10^{4}$ cells/well on 96-well plates in a final volume of $100 \mu \mathrm{L} /$ well. At the end of the treatments, each sample was added dichlorofluorescein diacetate (DCFH-DA, $1 \mathrm{mM}$ ) and placed in the dark for $10 \mathrm{~min}$ at room temperature. After washing with PBS, the cells were analyzed by the fluorescence Zeiss Axio Scope 2 microscope (Carl Zeiss, Oberkochen, Germany) and using a Microplate Reader GloMax fluorimeter (Promega Corporation, Madison, WI 53711 USA) at the excitation wavelength of $475 \mathrm{~nm}$ and emission wavelength $555 \mathrm{~nm}$ for fluorescence intensity detection. Results were expressed as a percentage of the control group.

\subsection{Oxidation Kinetics}

The oxidation kinetics was investigated by placing SH-SY5Y cells at a density of $2 \times 10^{4}$ cell/well on 96-well plates in a final volume of $100 \mu \mathrm{L} /$ well. At the end of the treatment, the kinetics of ROS production was evaluated for $2 \mathrm{~h}$ after the addition of 2,7-dichloro-diidrofluorescineacetate (DCFH-DA, Merck, Darmstadt, Germany) using the Microplate Reader GloMax fluorimeter (Promega Corporation, Madison, WI 53711 USA) at the excitation wavelength of $475 \mathrm{~nm}$ and emission wavelength $555 \mathrm{~nm}$.

\subsection{Mitochondrial Analysis}

\subsubsection{Mitochondrial Membrane Potential Analysis}

The mitochondrial transmembrane potential was measured by plating and treating the cells as mentioned above. After $\mathrm{H}_{2} \mathrm{O}_{2}$ treatment, the cells were incubated for 30 min at $37^{\circ} \mathrm{C}$ with $2 \mathrm{mM} \mathrm{JC}-1$ red dye (5, $5^{\prime}, 6,6^{\prime}$-tetrachloro-1,1',3,3'-tetraethylbenzimidazolylcarbocyanine iodide) using the MitoProbe JC-1 assay kit (Molecular Probes, USA). CCCP (carbonyl cyanide 3-chlorophenylhydrazone, $50 \mu \mathrm{M}$ ), a mitochondrial membrane potential disrupter, was used as positive control [25]. Fluorescence emission shift of JC-1 from red (590 nm) to green $(529 \mathrm{~nm})$ was evaluated by the aforementioned fluorimeter and fluorescence microscope equipped with a $488 \mathrm{~nm}$ excitation laser. 


\subsubsection{Mitochondrial Morphology Analysis}

Cellular mitochondria were stained using the MitoTracker Deep Red (Invitrogen, Carlsbad, CA, USA) dye ( $20 \mathrm{nM})$ for $15 \mathrm{~min}$, washed twice with growth medium, and observed under the fluorescence microscope (488 nm excitation/ $590 \mathrm{~nm}$ emission). Original fluorescence images were converted to binary images. Mitochondrial shapes were obtained by visualizing the mitochondria outlines automatically drawn by the ImageJ software (Public Domain, BSD-2 license, National Institutes of Health, Bethesda, MD, USA). Morphometric mitochondria data, length and perimeter, were calculated from each mitochondrial outline (N 500).

\subsubsection{Remodeling of Isolated Mitochondria}

The remodeling of isolated mitochondria was evaluated according to a published protocol [26], by measuring the changes in the absorbance of the mitochondrial suspensions at $540 \mathrm{~nm}$ using a GloMax Discover multimode plate reader (Promega, Italy). Briefly, a volume corresponding to $20 \mu \mathrm{g}$ of mitochondrial proteins was incubated with $50 \mu \mathrm{L}$ of PBS $\mathrm{pH}$ 7.4. The absorbance was monitored for $5 \mathrm{~min}$ at $37^{\circ} \mathrm{C}$ at $540 \mathrm{~nm}$, and the mitochondrial remodeling was indicated by a decrease in the absorbance.

\subsection{Pectin Sructural Characterization}

The molecular structure of four lemon IntegroPectin samples (two replicas of two batches) and a commercial pectin (Acros Organics) was characterized by Diffuse Reflectance Infrared Fourier Transform (DRIFT) spectroscopy, using a Mattson RS1 FTIR spectrometer (Mattson Instruments, Madison, WI, USA) equipped with a wide band MCT detector and a Specac selector, in the 4000 to $500 \mathrm{~cm}^{-1}$ range, at $4 \mathrm{~cm}^{-1}$ resolution. The spectra were the result of ratioing 500 co-added single beam scans for each sample (ground pectin powder diluted in grinded FTIR grade $\mathrm{KBr}$, in the appropriate proportion to assure the validity of the Kubelka-Munk assumptions) against the same number of scans for the background (grinded $\mathrm{KBr}$ ). The spectra were converted to Kubelka-Munk units and further processed using Microsoft Excel.

\subsection{Statistical Analysis}

Data analysis was performed using GraphPad Prism 8 software (GraphPad Software, San Diego, CA, USA). The results are presented as mean $\pm \mathrm{SE}$, and in some cases are expressed as arbitrary units, with controls equal to 1 , or as percentage of control. Statistical evaluations were performed by one-way ANOVA, followed by Tukey Post-Hoc test. Differences in $p$-value less than 0.05 were considered statistically significant.

\section{Results}

3.1. Effect of Pectins on Cell Viability upon Treatment with $\mathrm{H}_{2} \mathrm{O}_{2}$

We carried out a dose-effect investigation on SH-SY5Y cells [27] viability in response to treatment with commercial citrus pectin and lemon IntegroPectin testing the following doses via the MTT cell sensitivity assay [28]: 0.01, 0.1 , and $1 \mathrm{mg} / \mathrm{mL}$ for $24 \mathrm{~h}$ of contact. Results in Figure 1a,c show evidence that both pectins did not induce any significant change in cell viability. Figure $1 \mathrm{~b}$,d show that continuing the pectin treatment for the subsequent $24 \mathrm{~h}$ at pectin dose of $1 \mathrm{mg} / \mathrm{mL}$, did not induce any significant change in cell viability.

We, thus, tested the neuroprotective effect of pectin pretreatment (Figure 2a) or cotreatment (Figure $2 \mathrm{~b}$ ). Pretreatment of citrus pectin at both $1 \mathrm{mg} / \mathrm{mL}$ and $0.1 \mathrm{mg} / \mathrm{mL}$ dose was not effective in rescuing cell viability impaired by the biocidal action of $\mathrm{H}_{2} \mathrm{O}_{2}$. On the contrary, lemon IntegroPectin pretreatment at the same doses induced a significant, dose-dependent increase in cell viability compared to $\mathrm{H}_{2} \mathrm{O}_{2}$-treated cells. Interestigly, pretretament with lemon IntegroPectin was neuroprotective both when $\mathrm{H}_{2} \mathrm{O}_{2}$ was added to the medium containing the lemon IntegroPectin (Figure 2c), and when the medium containing the lemon IntegroPectin was removed and replaced with medium containing $\mathrm{H}_{2} \mathrm{O}_{2}$ (data not shown). Similar results were obtained when pectins were co-administered 
with $\mathrm{H}_{2} \mathrm{O}_{2}$ (co-treatment, Figure 2d). On the contrary, none of the the tested doses of both lemon IntegroPectin and citrus pectin were effective in protecting cells from $\mathrm{H}_{2} \mathrm{O}_{2}$-induced death when administered $3 \mathrm{~h}$ after $\mathrm{H}_{2} \mathrm{O}_{2}$ exposure (data not shown). Based on these results, the pectin dose chosen for all subsequent protection experiments was $1 \mathrm{mg} / \mathrm{mL}$.

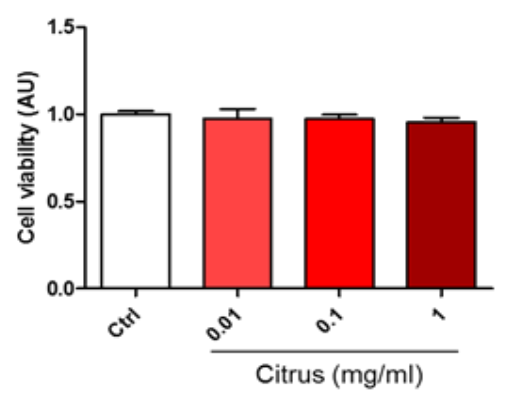

(a)

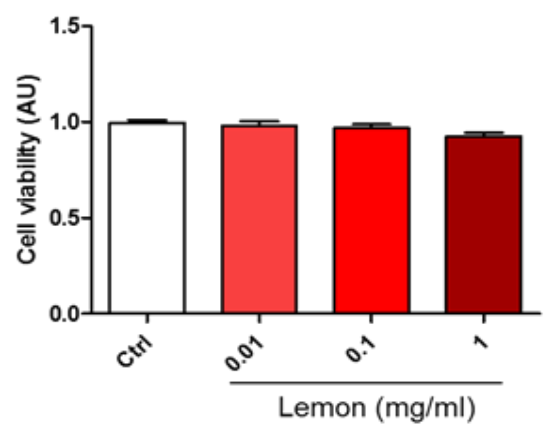

(c)

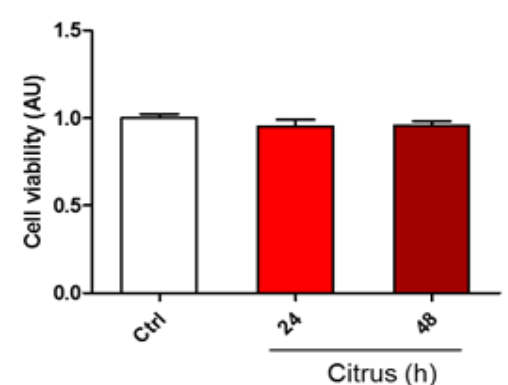

(b)

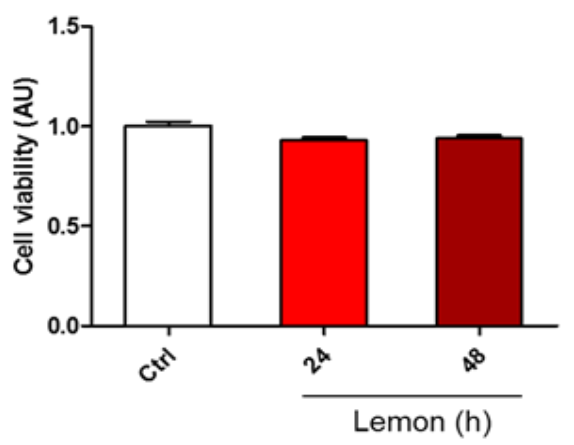

(d)

Figure 1. Dose and time dependent effects of commercial (citrus) and lemon IntegroPectin (lemon) pectins on neuronal cell viability: (a) Cell viability of citrus in dose dependent experiment; (b) Cell viability of citrus in time dependent experiment; (c) Cell viability of Lemon IntegroPectin in dose dependent experiment; (d) Cell viability of Lemon IntegroPectin in time dependent experiment.

\subsection{Effects of Pectins on Cell Morphology Impaired by $\mathrm{H}_{2} \mathrm{O}_{2}$ Treatment}

Since according to the MTT assay, pretreatment or co-treatment with lemon Integropectin increases cell viability, we next assessed the effect of pectin treatment on cell morphology by evaluating the cell body size (Figure $3 \mathrm{a}, \mathrm{d}$ ). Figure $3 \mathrm{a}, \mathrm{b}$ show evidence that pretreatment of the cells with commercial citrus pectin was not able to recover cell morphology severely impacted by the $\mathrm{H}_{2} \mathrm{O}_{2}$ treatment. On the contrary, pretreatment of the neuronal cells with lemon IntegroPectin completely protected the neuronal cells with full retention of the cell body size (Figure $3 b$ ). We, thus, counted the number of spheroidal debris particles in each for field image, indicative of cell disintegration and death. Figure $3 c$ shows evidence that pretreatment with lemon IntegroPectin totally prevented $\mathrm{H}_{2} \mathrm{O}_{2}$-induced increase in cell debris, whereas pretreatment with citrus pectin displayed only a partial neuroprotective effect. Figure 3d,e show that co-treatment of the cells with commercial citrus pectin was not able to recover cell morphology severely impacted by the $\mathrm{H}_{2} \mathrm{O}_{2}$ treatment. On the contrary, pretreatment of the neuronal cells with lemon IntegroPectin significantly protected the neuronal cells with and rescued cell body size (Figure 3e). 


\section{Pretreatment}

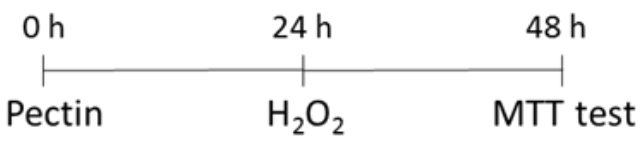

(a)

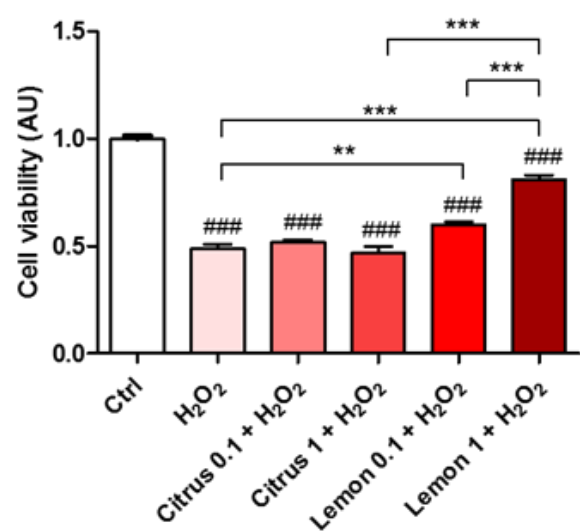

(c)

\section{Co-treatment}

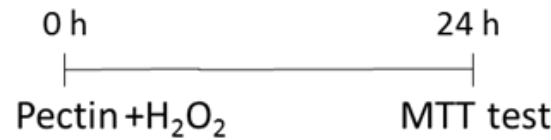

(b)

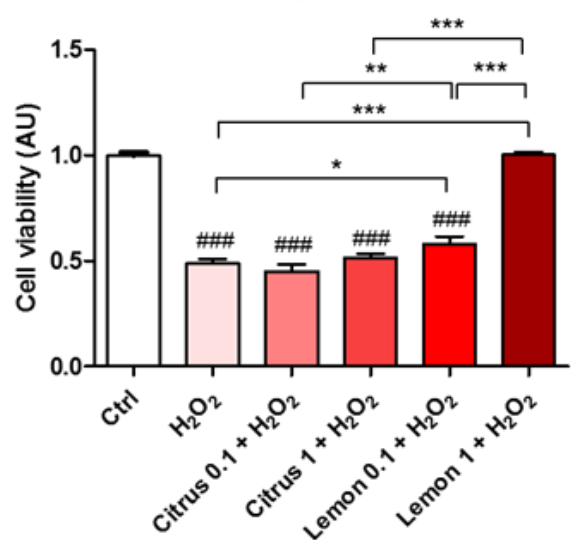

(d)

Figure 2. Oxidative insult during pretreatment and co-treatment with commercial (citrus) and lemon IntegroPectin (lemon) pectins: (a) Scheme of cell pretreatment with pectins; (b) Scheme of cell cotreatment with pectins; (c) Cell viability of pretreatment in dose dependent experiment; (d) Cell viability of co-treatment in dose dependent experiment. Tukey test: \#\#\# $p<0.001$ as compared to control (Ctrl) group; ${ }^{*} p<0.05,{ }^{* *} p<0.01,{ }^{* * *} p<0.001$.

Figure $3 \mathrm{f}$ shows that co-treatment of the neuronal cells with both pectic polymers in solution and aqueous $\mathrm{H}_{2} \mathrm{O}_{2}$ partially counteracted $\mathrm{H}_{2} \mathrm{O}_{2}$-induced increase in cell debris, with the effect of lemon IntegroPectin being significant more pronounced than that of citrus pectin. The presence of the cell debris was confirmed by the DNA cellular nuclear staining showing that treatment with $\mathrm{H}_{2} \mathrm{O}_{2}$ induced indeed increase in DNA damaging with degenerate nuclei being iperintense and fragmented. This condiction is reverted only by pretreatment or co-treatment with lemon IntegroPectin (Figure A1a,b), clearly indicating a DNA protection effect of the newly discovered pectin.

\subsection{Effects of Pectins on ROS Production Induced by $\mathrm{H}_{2} \mathrm{O}_{2}$ Treatment}

The impact of pectins on $\mathrm{H}_{2} \mathrm{O}_{2}$-induced oxidative stress was assessed measuring ROS production by DCFH-DA fluorescence intensity assay. Fluorescence microscope inspection (Figure 4a) and fluorescence intensity measurement (Figure $4 \mathrm{~b}$ ) show that pretreatment of neuronal cells with lemon IntegroPectin almost completely hindered the ROS increase driven by $\mathrm{H}_{2} \mathrm{O}_{2}$ addition, while pretreatment with commercial citrus pectin only partially prevented it.

The kinetics of ROS production after exposure of the neuronal cells to $\mathrm{H}_{2} \mathrm{O}_{2}$ shows a quick and rapidly accelerating increase in ROS production (purple curve in Figure 4c). Pretreatment with commercial citrus pectin does not prevent rapid ROS accumulation, though the final amount of ROS, during the first $2 \mathrm{~h}$ of treatment, is lower than with $\mathrm{H}_{2} \mathrm{O}_{2}$ alone (brown curve in Figure 4c). Pretreatment with lemon IntegroPectin is particularly effective in lowering and delaying ROS production driven by H2O2 (green curve in Figure 4c). The ROS generation plot is linear and the growth rate is slow. 


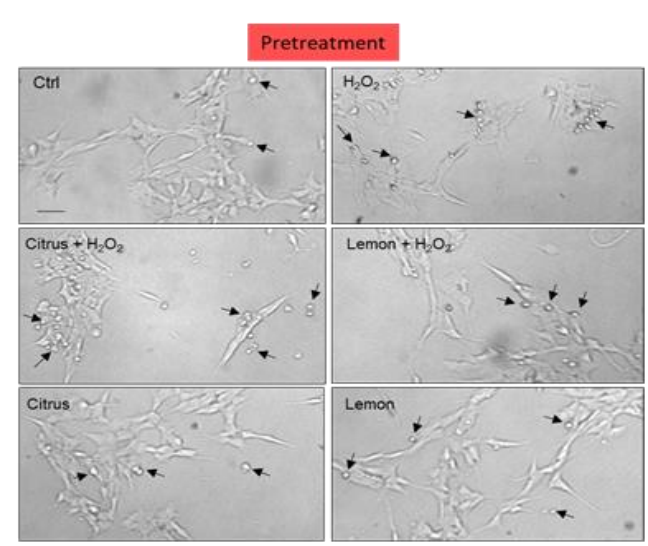

(a)

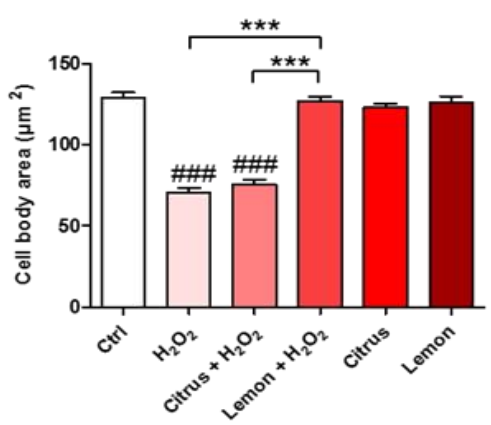

(b)

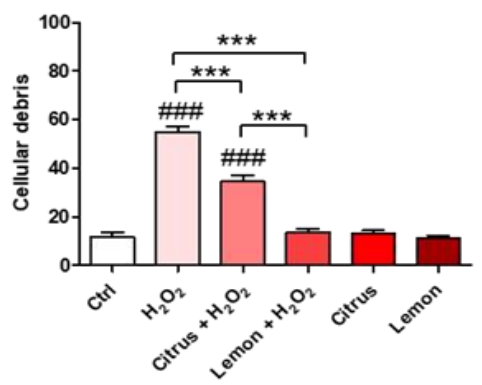

(c)

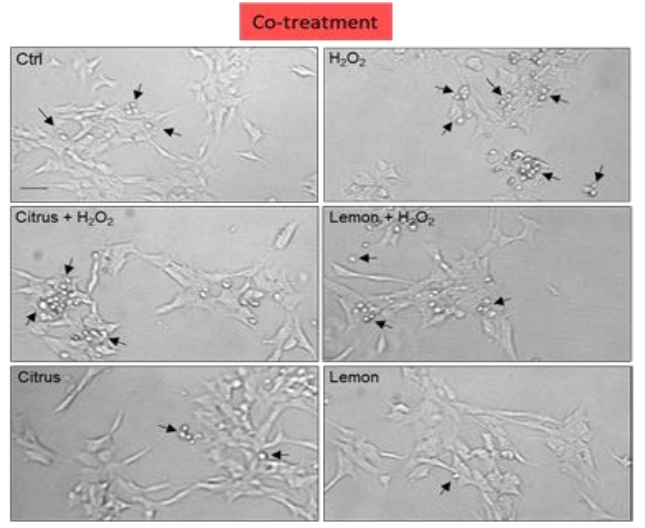

(d)

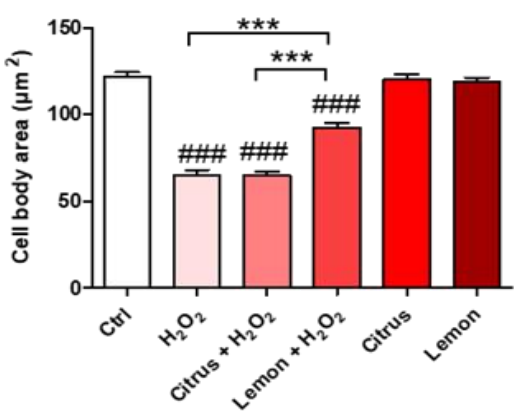

(e)

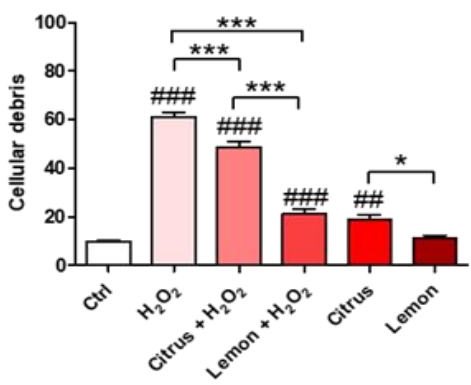

(f)

Figure 3. Effects of commercial (citrus) and lemon IntegroPectin (lemon) pectins on neuronal cell morphology in pretreatment and co-treatment: (a) Representative morphological images of the pretreatment of untreated cells (Ctrl) or treated with pectins or with $\mathrm{H}_{2} \mathrm{O}_{2}$ alone or in combination with pectins; examples of cell debris are indicated by arrows; (b) Histogram of the pretreatment of untreated cells (Ctrl) or treated or with $\mathrm{H}_{2} \mathrm{O}_{2}$ alone or in combination with pectins, cell body area; (c) Histogram of the pretreatment of untreated cells (Ctrl) or treated or with $\mathrm{H}_{2} \mathrm{O}_{2}$ alone or in combination with pectins, number of cells debris; (d) Representative morphological images of co-treatment of untreated cells (Ctrl) or treated with pectins or with $\mathrm{H}_{2} \mathrm{O}_{2}$ alone or in combination with pectins; examples of cell debris are indicated by arrows; (e) Histogram of the co-treatment of untreated cells (Ctrl) or treated or with $\mathrm{H}_{2} \mathrm{O}_{2}$ alone or in combination with pectins, cell body area; (f) Histogram of the co-treatment of untreated cells (Ctrl) or treated or with $\mathrm{H}_{2} \mathrm{O}_{2}$ alone or in combination with pectins, number of cells debris. Bar: $50 \mu \mathrm{m}$. Tukey test: \#\# $p<0.01$, \#\# $p<0.001$ as compared to control (Ctrl) group; ${ }^{*} p<0.05,{ }^{* * *} p<0.001$. 


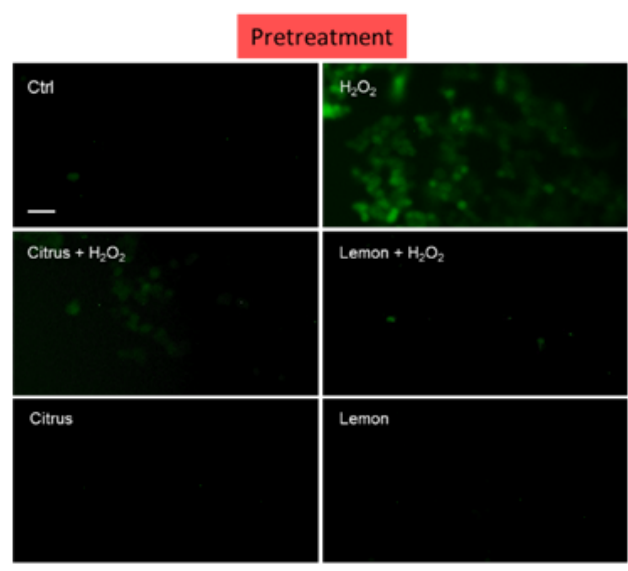

(a)

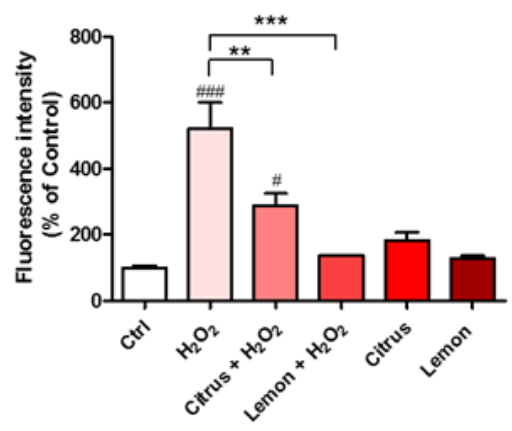

(b)

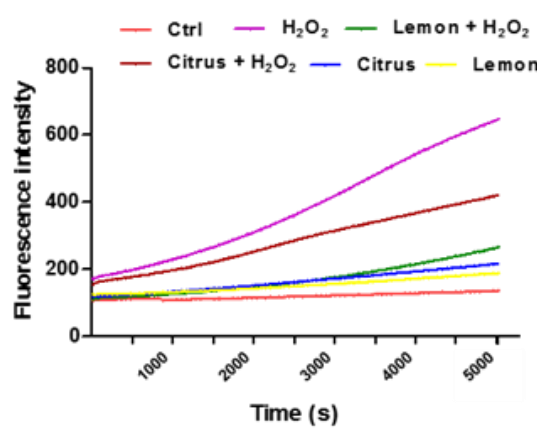

(c)

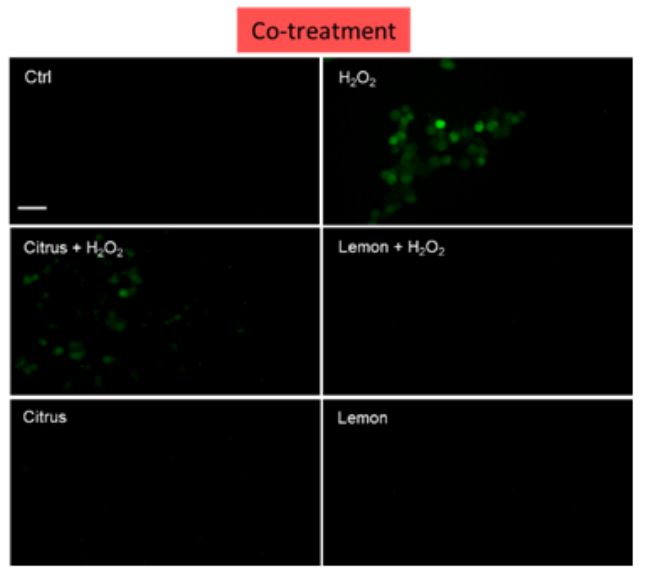

(d)

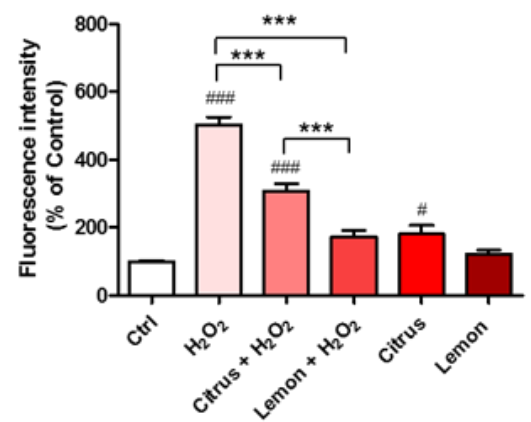

(e)

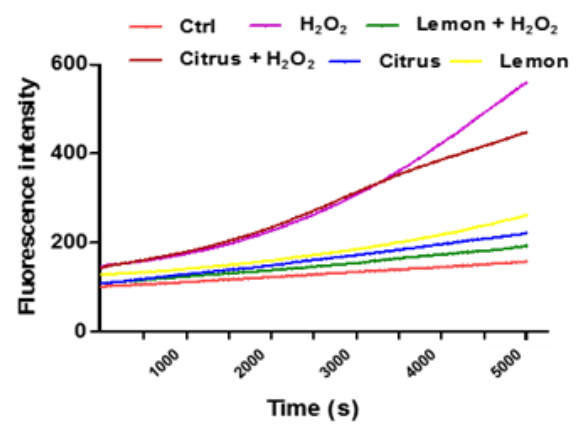

(f)

Figure 4. Effects of commercial (citrus) and lemon IntegroPectin (lemon) pectins on ROS production driven by exposure to aqueous $\mathrm{H}_{2} \mathrm{O}_{2}$ : (a) fluorescence microscopy images of the pretreatment of untreated cells (Ctrl) or treated with pectins or with $\mathrm{H}_{2} \mathrm{O}_{2}$ alone or in combination with pectins; (b) fluorescence intensity of the pretreatment of untreated cells (Ctrl) or treated with pectins or with $\mathrm{H}_{2} \mathrm{O}_{2}$ alone or in combination with pectins measured by the DCFH-DA fluorescence assay; (c) oxidation kinetics of the pretreatment of untreated cells (Ctrl) or treated with pectins or with $\mathrm{H}_{2} \mathrm{O}_{2}$ alone or in combination with pectins; (d) fluorescence microscopy images of the co-treatment of untreated cells (Ctrl) or treated with pectins or with $\mathrm{H}_{2} \mathrm{O}_{2}$ alone or in combination with pectins; (e) fluorescence intensity of the co-treatment of untreated cells (Ctrl) or treated with pectins or with $\mathrm{H}_{2} \mathrm{O}_{2}$ alone or in combination with pectins measured by the DCFH-DA fluorescence assay; (f) oxidation kinetics of the co-treatment of untreated cells (Ctrl) or treated with pectins or with $\mathrm{H}_{2} \mathrm{O}_{2}$ alone or in combination with pectins. Bar: $50 \mu \mathrm{m}$. Tukey test: \#p<0.05,\#\# $p<0.001$ as compared to control (Ctrl) group; ${ }^{* *} p<0.01,{ }^{* * *} p<0.001$. 
Neuronal cells co-treated with lemon IntegroPectin did not show any increase in fluorescence intensity when concomitantly exposed to aqueous $\mathrm{H}_{2} \mathrm{O}_{2}$ (Figure $4 \mathrm{~d}$,e). In contrast, cells co-treated with commercial citrus pectin showed a partial reduction of green fluorescence, indicative of ROS generation.

The kinetics of ROS production after exposure of the neuronal cells to $\mathrm{H}_{2} \mathrm{O}_{2}$ show that co-treatment of neuronal cells with lemon IntegroPectin counteracted ROS increase driven by $\mathrm{H}_{2} \mathrm{O}_{2}$ (green curve in Figure $4 \mathrm{f}$ ). In contrast, co-treatment of the neuronal cells with commercial citrus pectin and hydrogen peroxide was almost completely ineffective in preventing or delaying ROS generation (purple curve in Figure 4f).

\subsection{Effects of Pectins on Mitochondrial Membrane Potential Altered by $\mathrm{H}_{2} \mathrm{O}_{2}$ Treatment}

Exacerbated ROS production damages mitochondrial components generating dysfunctional mitochondrial units. The exposure to excessive oxidative stress results in an increase in ROS concentration until a threshold level is reached that triggers the opening of the mitochondrial permeability transition pore (MPTP), leading to the collapse of the mitochondrial membrane potential and subsequent release of cytochrome $C$ into the cytosol, which in turn initates other cellular events in the apoptotic cascade [29]. Variations in the physiological mitochondrial membrane potential, an indicator of cells' health and functional status [30], were, therefore, measured as changes in the accumulation of JC- 1 cyanine dye red and green fluorescence signals in the cells. Mitochondrial toxin CCCP was used as a positive control. Mitochondria are sensitive to ROS, mostly generated as a byproduct of cellular respiration. We briefly remind that when excited at $488 \mathrm{~nm}$, JC-1 monomers emit green fluorescence with a maximum at $530 \mathrm{~nm}$ (green), whereas J-aggregates emit orange-red fluorescence with a maximum at $595 \mathrm{~nm}$ (orange-red) [30]. The green fluorescent JC-1 dye forms red fluorescent aggregates when concentrated in energized mitochondria in response to their higher membrane potential.

As displayed by Figure 5a,b, treatment of the neuronal cells with either commercial citrus pectin or lemon IntegroPectin did not alter JC-1 red/green fluorescent signal, indicating absence of mitotoxicity of both pectins. Figure $5 c$,d show that the JC- 1 red/green fluorescent signal significantly diminished following cell exposure to $\mathrm{H}_{2} \mathrm{O}_{2}$. Pretreatment of the cells with commercial citrus pectin and further exposed to aqueous $\mathrm{H}_{2} \mathrm{O}_{2}$ did not counteract the reduction of the red/green fluorescent signal. Pretreatment of the neuronal cells with lemon IntegroPectin, however, significantly reversed this effect. Figure 5e,f show that co-treatment of the cells with lemon IntegroPectin and $\mathrm{H}_{2} \mathrm{O}_{2}$ totally counteracted the $\mathrm{H}_{2} \mathrm{O}_{2}$-driven reduction of the red/green fluorescent signal. On the other hand, when commercial citrus pectin was co-administered to the neuronal cells along with aqueous $\mathrm{H}_{2} \mathrm{O}_{2}$ it was virtually ineffective in preventing the red/green signal reduction, which turned out to be nearly identical to that driven by treatment with $\mathrm{H}_{2} \mathrm{O}_{2}$ alone.

\subsection{Effects of Pectins on Mitochondrial Morphology Induced by $\mathrm{H}_{2} \mathrm{O}_{2}$ Treatment}

Changes in mitochondrial morphology occur in many neurological diseases including Alzheimer's [31] and Parkinson's [32] diseases and amyotrophic lateral sclerosis [33]. We, thus, analyzed mitochondrial remodeling by measuring the absorbance of isolated mitochondria. Figure $6 \mathrm{a}, \mathrm{b}$ show evidence that pretretment and co-treatment with lemon IntegroPectin fully counteracted the significant $\mathrm{H}_{2} \mathrm{O}_{2}$-induced mitochondrial remodeling. On the contrary, citrus pectin failed in producing a similar effect. 


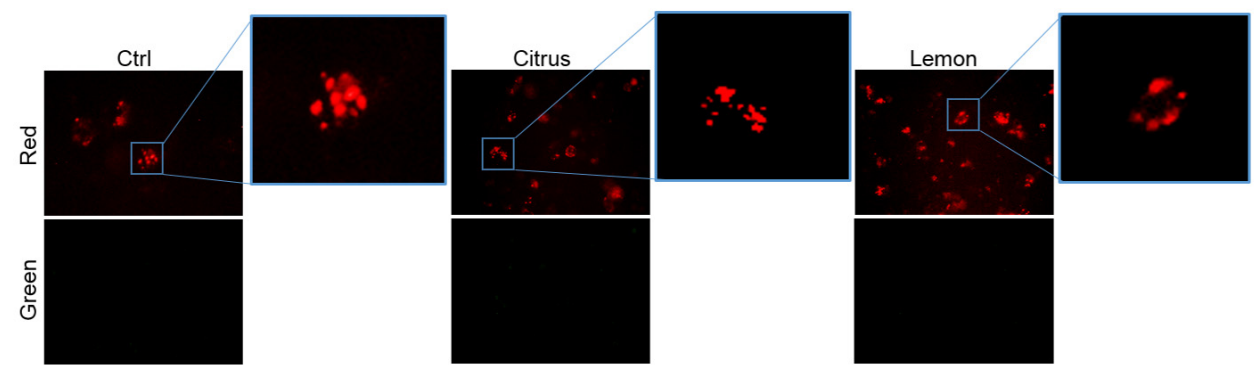

(a)

\section{Pretreatment}

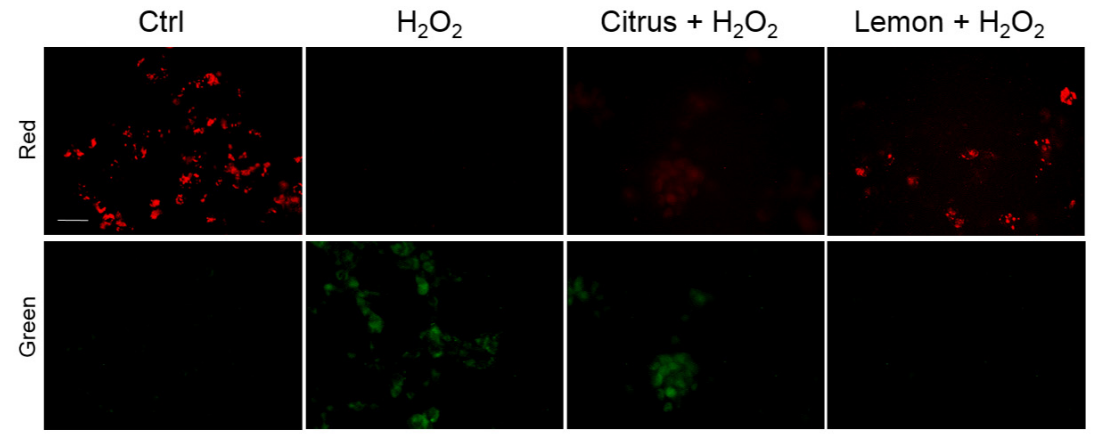

(c)

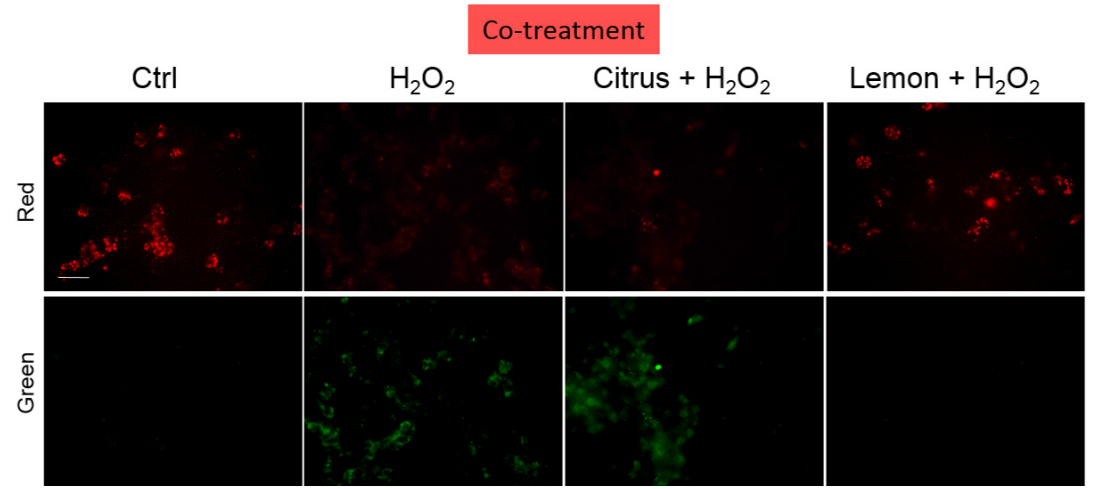

(e)

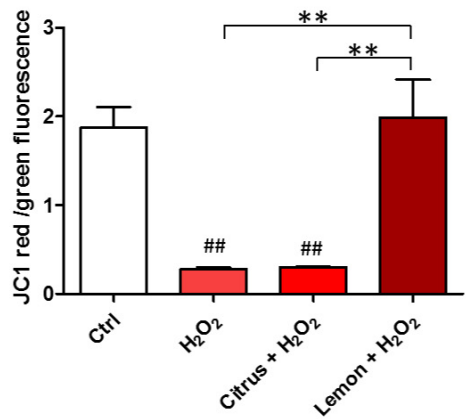

(d)

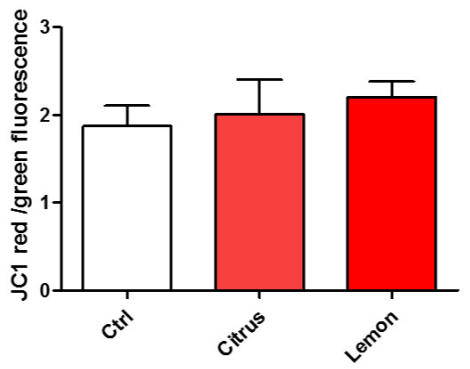

(b)

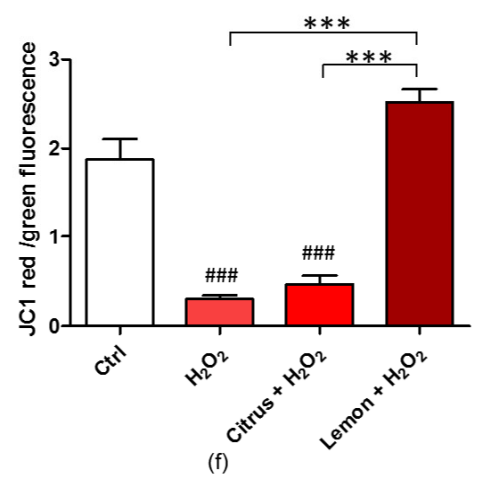

Figure 5. Effects of commercial (citrus) and lemon IntegroPectin (lemon) pectins on JC-1 red and green fluorescence affected by exposure to aqueous $\mathrm{H}_{2} \mathrm{O}_{2}$ : (a) Fluorescence microscope inspection of cells treated with pectins alone submitted to JC-1 assay, the magnifications highlight the shape of the mitochondria, (b) histogram representing the ratio between red and green fluorescence intensity; (c) Fluorescence microscope inspection of cells untreated (Ctrl), treated with $\mathrm{H}_{2} \mathrm{O}_{2}$ alone, or pretreated with pectins and then with $\mathrm{H}_{2} \mathrm{O}_{2}$ submitted to JC-1 assay; (d) histogram representing the ratio between red and green fluorescence intensity in pretreatment experiment; (e) fluorescence microscope examination of cells untreated (Ctrl), treated with $\mathrm{H}_{2} \mathrm{O}_{2}$ alone or co-treated with pectins and $\mathrm{H}_{2} \mathrm{O}_{2}$ submitted to JC- 1 assay; (f) histogram representing the ratio between red and green fluorescence intensity in cotreatment experiment. Bar: $100 \mu \mathrm{m}$. Tukey test: \#\# $p<0.01$, \#\#\# $p<0.001$ as compared to control (Ctrl) group; ${ }^{* *} p<0.01$, *** $p<0.001$. 


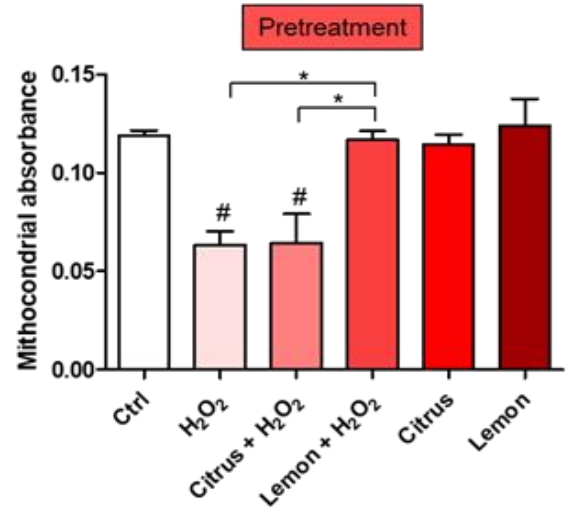

(a)

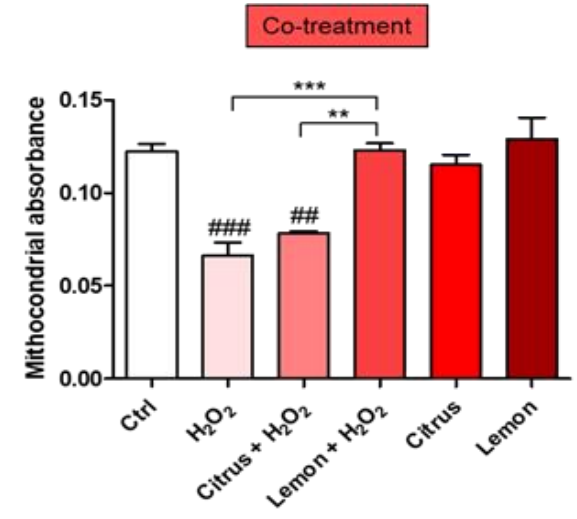

(b)
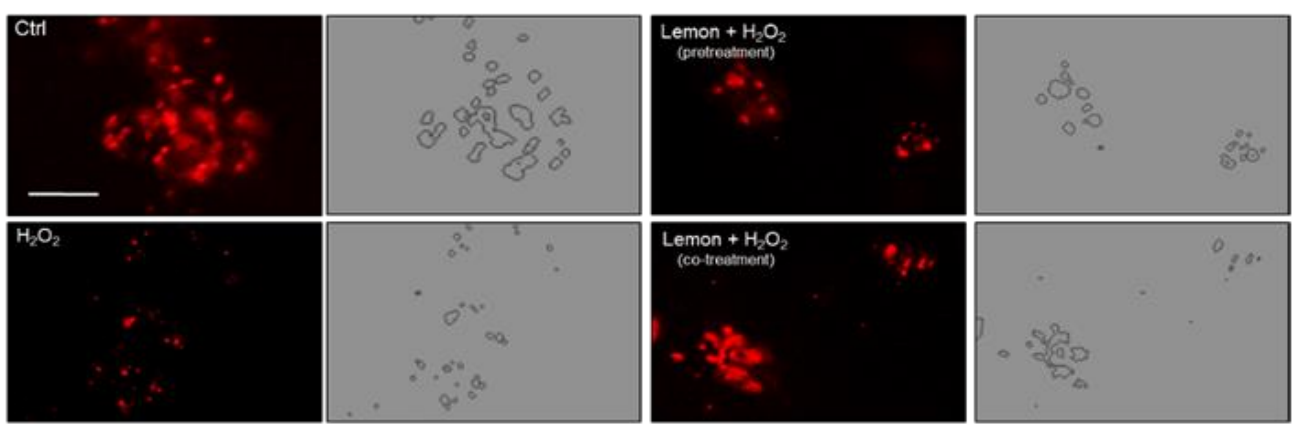

(c)

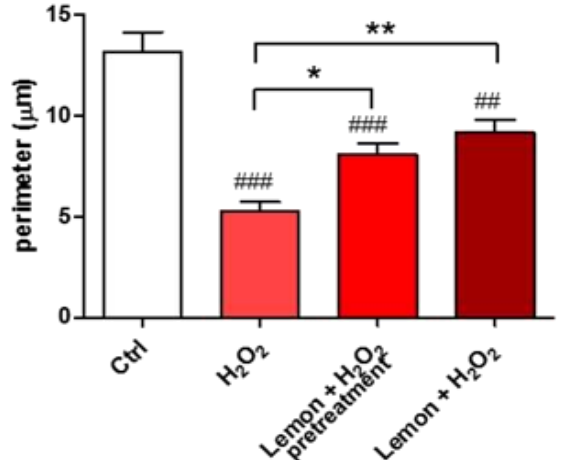

(d)

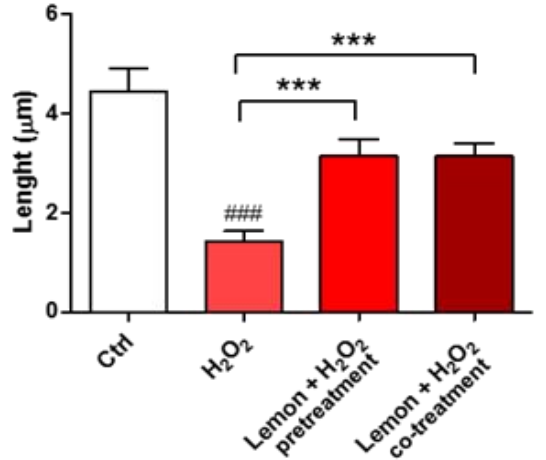

(e)

Figure 6. Effects of commercial (citrus) and lemon IntegroPectin (lemon) pectins on mitochondrial morphology and remodeling affected by exposure to aqueous $\mathrm{H}_{2} \mathrm{O}_{2}$ : (a) Mitochondria remodeling of the pretreatment of untreated cells (Ctrl) or treated with pectins or with $\mathrm{H}_{2} \mathrm{O}_{2}$ alone or in combination with pectins; (b) Mitochondria remodeling of the co-treatment of untreated cells (Ctrl) or treated with pectins or with $\mathrm{H}_{2} \mathrm{O}_{2}$ alone or in combination with pectins; (c) Representative fluorescence microscopy images of mitochondria stained with the MitoTracker Deep Red in untreated cells (Ctrl) or treated with $\mathrm{H}_{2} \mathrm{O}_{2}$ alone or in combination with lemon IntegroPectin (pretreatment and co-treatment); (d,e) Histograms representing quantification of mitochondria perimeter and length, respectively, in untreated cells (Ctrl) or treated with $\mathrm{H}_{2} \mathrm{O}_{2}$ alone or in combination with lemon IntegroPectin

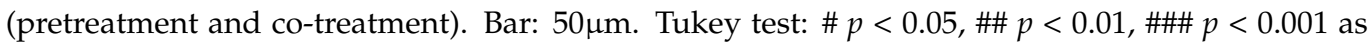
compared to control (Ctrl) group; ${ }^{*} p<0.5,{ }^{* *} p<0.01,{ }^{* * *} p<0.001$. 
In light of better results obtained with lemon IntegroPectin, we analyzed its effect on the mitochondrial morphology both via cell pretreatment or co-treatment. As shown in Figure $6 c$, the morphology of mitochondria, stained with MitoTracker dyes in neuronal cells, during normal culture conditions is characterized by a well interconnected mitochondrial network. Treatment of the cells with aqueous $\mathrm{H}_{2} \mathrm{O}_{2}$ resulted in a concomitant change in mitochondrial morphology from tubular networks to fragmented puncta (circular). Remarkably, whereas a reduction in perimeter and length of the mitochondria was clearly observed after the cell treatment with hydrogen peroxide (picture in the bottom left, Figure $6 \mathrm{c}$ ), when lemon IntegroPectin was administered immediately before or directly along with the strong oxidizer $\mathrm{H}_{2} \mathrm{O}_{2}$, the morphology and mitochondrial parameters were partially recovered (Figure $6 \mathrm{~d}, \mathrm{e}$ ).

\subsection{Structural Insight}

To interpret the outstanding properties of lemon IntegroPectin, we analyzed the molecular structure of two batches of lemon IntegroPectin (lemon-A and lemon-B). Figure 7 compares these spectra with that of a commercial (citrus) pectin. The $4000-2100 \mathrm{~cm}^{-1}$ region was normalized to the hydroxyl stretching band, and the $1850-500 \mathrm{~cm}^{-1}$ region was normalized to the carbonyl stretching band. The 4000 to $2100 \mathrm{~cm}^{-1}$ spectral region is dominated by the broad and intense O-H stretching band of hydroxyls, overlapped with the C-H stretching band. The broad shoulder near $2550 \mathrm{~cm}^{-1}$, observed only in lemon IntegroPectin may be assigned to the $\mathrm{O}-\mathrm{H}$ stretching vibration in free carboxyl groups [34]. The two strong bands in the $1750-1500 \mathrm{~cm}^{-1}$ region are assigned to stretching modes of carbonyl groups from esterified D-GalA units and free carboxylate groups, respectively [35]. The main $\mathrm{CH}_{\mathrm{X}}$ and $\mathrm{C}-\mathrm{O}-\mathrm{H}$ deformation modes appear partially overlapped, in the $1500-1200 \mathrm{~cm}^{-1}$ region.

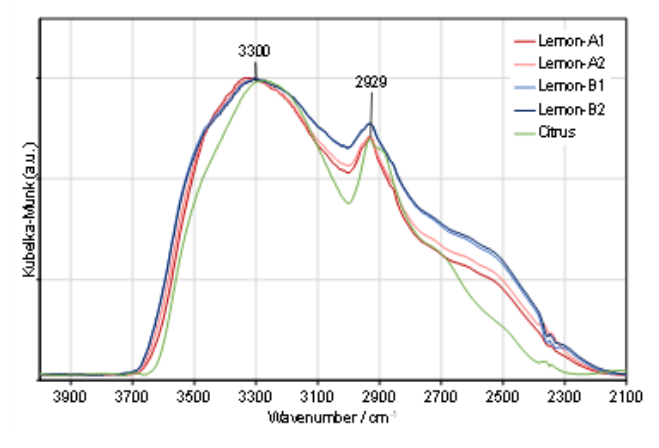

(a)

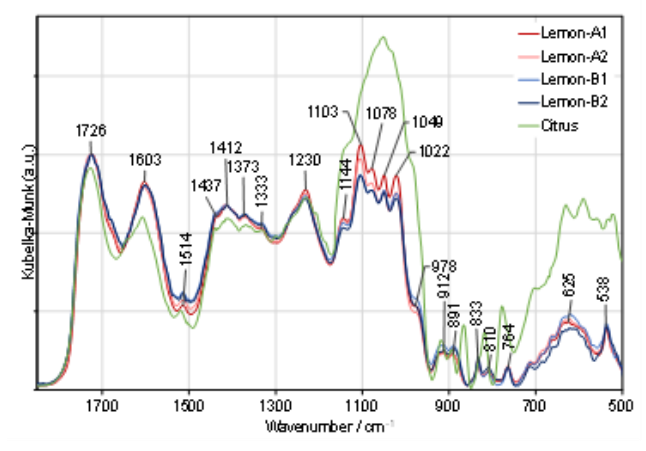

(b)

Figure 7. Comparison of the DRIFT spectra of lemon IntegroPectin (Lemon-A and Lemon-B) and commercial (Citrus) pectin: (a) $4000-2100 \mathrm{~cm}^{-1}$ and (b) $200-950 \mathrm{~cm}^{-1}$ spectral regions.

The five intense and partially overlapped bands observed in the $1200-950 \mathrm{~cm}^{-1}$ region are characteristic of the pectin backbone and side groups (Scheme 1). The band at $1144 \mathrm{~cm}^{-1}$ is assigned to the C-O-C stretching vibrations of the $\alpha-1,4-\mathrm{D}$-glycosidic bonds in the HG chains. The two strong bands at 1103 and $1022 \mathrm{~cm}^{-1}$ are due to skeletal stretching modes of the pyranose rings in D-GalA and L-Rha residues, present both in homogalacturonan (HG) and type I rhamnogalacturonan (RG-I) regions. The other two very intense bands, at 1078 and $1049 \mathrm{~cm}^{-1}$, result from neutral sugars in the side chains of RG-I and are assigned to the same stretching modes of L-arabinosyl and D-galactosyl units, respectively [36]. This region is less defined and more intense in the spectrum of the commercial (Citrus) pectin, giving additional information on the sugar structure of these pectins. As mentioned in previous publications, it is not possible to quantify the HG content of pectin just by infrared analysis. Nevertheless, the unique shape of the cyclic ethers spectral region $\left(1200-950 \mathrm{~cm}^{-1}\right)$, in conjunction with their relatively low intensity, suggests that lemon 
IntegroPectin pectin has a high proportion of type I rhamnogalacturonan containing sidechains of $\alpha-1,5-\mathrm{L}$-arabinosyl and $\beta-1,4$-D-galactosyl residues when compared with the commercial (citrus) pectin.

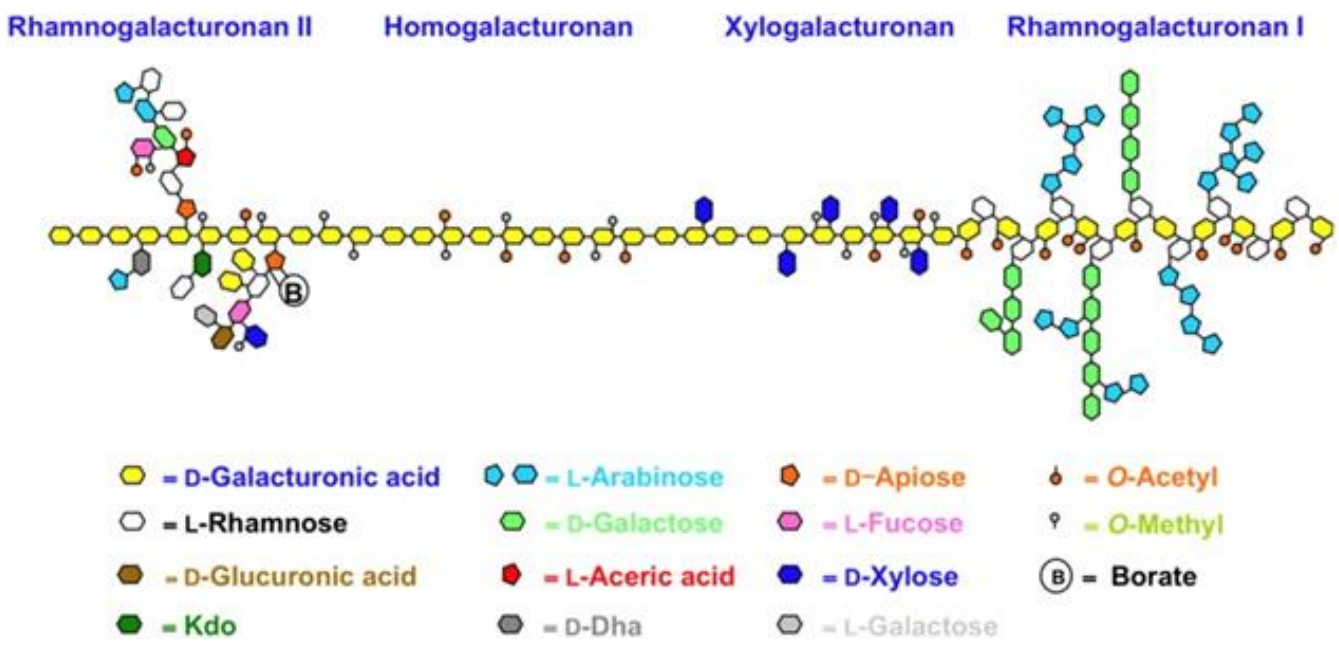

Scheme 1. Simplified structure of pectin.

The degree of esterification of pectin (percent of methyl-esterified carboxyl groups) was determined by the ratio of ester carboxyl to total carboxyl peak areas, estimated by decomposing the $1750-1500 \mathrm{~cm}^{-1}$ region into a sum of Gaussian components, using a nonlinear least-squares fitting. The main results, presented in Table 1 for the lemon IntegroPectin replicas, yield an average degree of esterification (DM) $27 \pm 3 \%$, much lower than that for the commercial (citrus) pectin, which is $69 \pm 2 \%$.

Table 1. Computed maximum $\left(\widetilde{v}, \mathrm{~cm}^{-1}\right)$, full width at half maximum $\left(\mathrm{FWHM}, \mathrm{cm}^{-1}\right)$, relative area $(\mathrm{A}, \%)$ and assignment of the bands obtained by decomposition into a sum of Gaussian components of the $1750-1500 \mathrm{~cm}^{-1}$ region.

\begin{tabular}{cccc}
\hline Infrared Component & $\tilde{\boldsymbol{v}} / \mathbf{c m}^{-\mathbf{1}}$ & FWHM/cm $^{\mathbf{- 1}}$ & Area \% \\
\hline$v(\mathrm{C}=\mathrm{O})_{\text {Methyl Ester }}$ & $1743.7 \pm 0.7$ & $44 \pm 3$ & $20 \pm 2$ \\
$v(\mathrm{C}=\mathrm{O})_{\text {Methyl Ester, H.bonded }}$ & $1715.7 \pm 0.8$ & $32 \pm 2$ & $6 \pm 2$ \\
$v(\mathrm{C}=\mathrm{O})_{\text {Acid }}$ & $1692 \pm 3$ & $61 \pm 6$ & $21 \pm 4$ \\
$v_{\text {as }}\left(\mathrm{COO}^{-}\right)$ & $1600 \pm 2$ & $101 \pm 5$ & $52 \pm 1$ \\
\hline
\end{tabular}

\section{Discussion}

In this study, we have demonstrated the neuroprotective and antioxidant effects of lemon IntegroPectin, an exceptionally powerful antioxidant obtained from organic lemon processing industrial waste using hydrodynamic cavitation.

Pectin extracted from citrus fruits is generally a high molecular weight (100 to $400 \mathrm{kDa}$ ) polymer, with HG proportions commonly ranging from 80 to $90 \%[35,37]$ and with a degree of methylation generally above $50 \%$, namely high methoxy $(\mathrm{HM})$ pectin. We briefly remind that pectin entitles a complex group of heteropolysaccharides containing at least eight different covalently inter-linked pectic polysaccharide types, of which HG, RG-I and, to a lesser extent, type II rhamnogalacturonan (RG-II) and/or xylogalacturonan (XGA) are the most common (Scheme 1) [38]. Typically, grapefruit and orange pectins extracted from dried citrus peel via conventional acid hydrolysis in hot water contain longer and more numerous RG-I polysaccharide chains than lemon pectin, affording lower intrinsic viscosity [39]. The pectin industry also supplies low methoxy (LM) citrus or apple pectin (average degree of esterification $\mathrm{DM}<50 \%$ ) using enzymatic or alkaline hydrolysis under controlled conditions. $\mathrm{HM}$ pectin gels at $\mathrm{pH}<3.5$, in the presence of a minimum 7 of 
$55 \%$ sugar, and is very unstable at $\mathrm{pH}>5$, where it will depolymerize rapidly upon heating. LM pectin tends to form gels electrostatically, stabilized by metal cations, and may gel at higher $\mathrm{pH}$ values. These structural characteristics and correlated properties vary according to the extraction procedure. In previous works, we have shown the advantages of hydrocavitation for improving the biological activity of citrus pectin [22,24]. The essential oils (EOs) emulsify in water during the hydrocavitation of citrus processing waste (CPW), with limonene (the main citrus EO component) and linalool being converted into highly bioactive $\alpha$-terpineol and terpinen-4-ol due to acid catalysis promoted by citric acid residual in the CPW enhanced by the implosion of the cavitation bubbles [40]. Freeze-dried pectin obtained along with flavonoids and said emulsified citrus oil upon lyophilization contains the integral water-soluble part of waste citrus peel, including the flavonoids in a highly concentrated fashion, and constitutes a completely new biomaterial, accordingly named "IntegroPectin" [22-24,40,41]. Furthermore, the DM of said citrus pectins extracted by hydrodynamic cavitation of wet citrus peel is significantly lower than $50 \%$.

The radical scavenging action of the IntegroPectin and of commercial citrus pectin, was investigated by in vitro experiments using the powerful oxidant $\mathrm{H}_{2} \mathrm{O}_{2}$. We also investigated the cell viability, cell morphology, and ROS production induced by treatment of neuronal SH-SY5Y human cells with $\mathrm{H}_{2} \mathrm{O}_{2}$ in the presence of the aforementioned pectins. Moreover, for the first time, we studied the effect of pectins on the mitochondrial dysfunction, a cellular mechanism involved in different neurological diseases. The mitochondrial dysfunction driven by $\mathrm{H}_{2} \mathrm{O}_{2}$ was blocked by the pretreatment or co-treatment with IntegroPectin. The newly sourced lemon discovered IntegroPectin inhibits the $\mathrm{H}_{2} \mathrm{O}_{2}-$ induced mitochondrial membrane damage, indicating that its radical scavenging effect is also extended to mitochondrial ROS. On the other hand, little or no mitochondrial protection was exerted by commercial citrus pectin. These data indicate that only lemon IntegroPectin exerts a protective role on the cell's central organelle, involved in several neurological dysfunctions.

We hypothesize that the neuroprotective action of lemon IntegroPectin is due to the combined action of $\alpha$-terpineol, hesperidin (and likely eriocitrin, too), and LM pectin. A neuroprotective [42] and anticholinergic (cholinesterase inhibitor) [43] agent, $\alpha$-terpineol has been lately shown to have antidepressant-like effects [44]. Hesperidin, along with eriocitrin $(16.7 \mathrm{mg} / 100 \mathrm{~mL})$ by far the most abundant flavonoid in lemon juice $(20.5 \mathrm{mg} / 100 \mathrm{~mL})$ [45], exerts its neuroprotective action by improving neural growth factors and endogenous antioxidant defense functions as well as by diminishing neuro-inflammatory and apoptotic pathways [46]. Hesperidin is being intensively studied also as a preventative and therapeutic agent against the development of various types of metabolic diseases [47]. Lemon-derived eriocitrin, known to increase antioxidant capacity and decrease inflammatory markers in mice [48], is along with hesperidin the main ingredient of a nutraceutical product recently shown to be effective, in a double-blind randomized clinical study, in managing hyperglycemia and reversal of prediabetes condition [49].

Besides the neuroprotective effects of ginseng pectin [16], low-methoxyl citrus pectin was lately shown to protect pancreatic cells against diabetes-induced oxidative and inflammatory stress via galectin-3 (Gal-3), a $\beta$-galactoside-binding lectin involved in cellular inflammation and apoptosis [50]. Most recently, scholars in China reported early evidence that plasma Gal-3 levels of Huntington's disease patients correlate with disease severity, and that suppression of Gal-3 suppresses inflammation, and restores neuronal DARPP32 levels, improving motor dysfunction, and increasing survival in mice affected by the disease. The team concluded that "Gal-3 is a novel druggable target for Huntington's disease" [51]. Pectin is a natural and specific inhibitor of Gal-3, via its multiple galactan side chains [52], and citrus pectins obtained via cavitation are particularly rich in RG-I side chains [53] when compared to citrus pectins obtained via conventional acid hydrolysis of the dried citrus peel, which results in the loss of most hydrophilic RG-I chains in favor of HG "smooth" regions. The RG-I regions of the pectin heteropolysaccharide, on the other hand, are preserved using green, acid-free extraction techniques such as 
microwave-assisted extraction [54], acoustic [53], and hydrodynamic [22-24] cavitation. In this regard, the low DE values observed for lemon and grapefruit IntegroPectin samples seem to indicate even greater preservation of RG-I chains through hydrodynamic cavitation in comparison with other extraction techniques.

Although we did not investigate the effects of lemon IntergroPectin on Gal-3 regulation, oxidative stress and neuroinflammation inhibition in primary neurons and glial cells (or on animal model of brain disorders), our preliminary observations on neuroblastoma cells suggest the applicative potential of these new bioactive extracts in the treatment of complex neurological pathologies. Numerous literature data reveals that many other natural biomolecules exhibit neuroprotective effects [55-58].

\section{Conclusions}

In conclusion, lemon IntegroPectin, an exceptionally powerful antioxidant obtained from (organic) lemon processing waste using hydrodynamic cavitation, exerts significant in vitro neuroprotective and mitoprotective action on neuronal SH-SY5Y human cells treated with aqueous $\mathrm{H}_{2} \mathrm{O}_{2}$, a strong oxidizer involved in the cellular mechanisms leading to neurodegenerative pathologies. The radical scavenging action of the IntegroPectin [24] was confirmed by the experiments on neuronal cells. The $\mathrm{H}_{2} \mathrm{O}_{2}$-induced mitochondrial dysfunction was blocked by the pretreatment or co-treatment with IntegroPectin, indicating that its scavenging effect is also extended to mitochondrial ROS. Moreover, this newly developed pectin inhibits $\mathrm{H}_{2} \mathrm{O}_{2}$-induced mitochondrial membrane damage. On the other hand, little or no protection was exerted by commercial citrus pectin indicating that only lemon IntegroPectin exerts a protective role on the cell's central organelle, involved in several pathological dysfunctions. We ascribe these findings to the combined action of the terpenes [40] and flavonoids [59] adsorbed at the surface of the pectic polymer as well as to the unique structure of this new pectin of low degree of esterification and with a more pronounced abundance of RG-I "hairy" regions rich in galactose and arabinose units, capable to bind and inhibit $\beta$-galactoside-binding lectin galectin-3. As recently remarked by Sobarzo-Sánchez and co-workers suggesting the need for further clinical trials, a few clinical studies have already shown that hesperidin-enriched dietary supplements can significantly improve cerebral blood flow, cognition, and memory performance [46]. In this respect, it is encouraging that lemon IntegroPectin did not show any toxic activity on the neuronal SH-SY5Y cell line studied even at high doses, likewise to what happens in the treatment of human epithelial pulmonary cells [24]. The effects of dietary supplementation with lemon IntegroPectin on the prevention and treatment of neurodegenerative diseases should be urgently investigated.

Author Contributions: Conceptualization, D.N. and V.D.L.; methodology, R.C.; formal analysis, C.G., M.S., G.M., L.M.I., A.F., A.P., A.S., R.A.; investigation, D.N., P.P., V.D.L., L.M.I., A.F.; resources, D.N., F.M., M.P.; data curation, D.N.; P.P., C.G., M.S., G.M.; writing-original draft preparation, D.N., M.P., V.D.L.; writing-review and editing, D.N., V.D.L. and M.P.; supervision, D.N., V.D.L. All authors have read and agreed to the published version of the manuscript.

Funding: This research received no external funding.

Institutional Review Board Statement: Not applicable.

Informed Consent Statement: Not applicable.

Data Availability Statement: All data are available by contacting the corresponding authors.

Acknowledgments: This study is dedicated to the memory of Natale Belluardo, neuroscientist and gentleman, for all he has done at Palermo's University. We thank OPAC Campisi (Siracusa, Italy) for kindly providing the lemon bagasse from which the lemon IntegroPectin was obtained.

Conflicts of Interest: The authors declare no conflict of interest. 


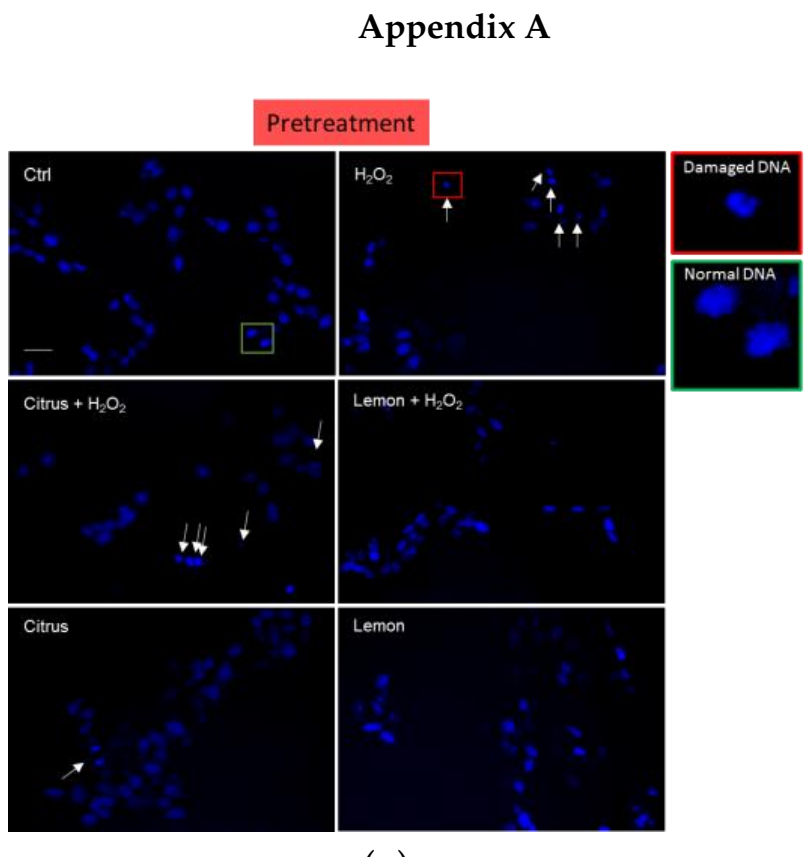

(a)

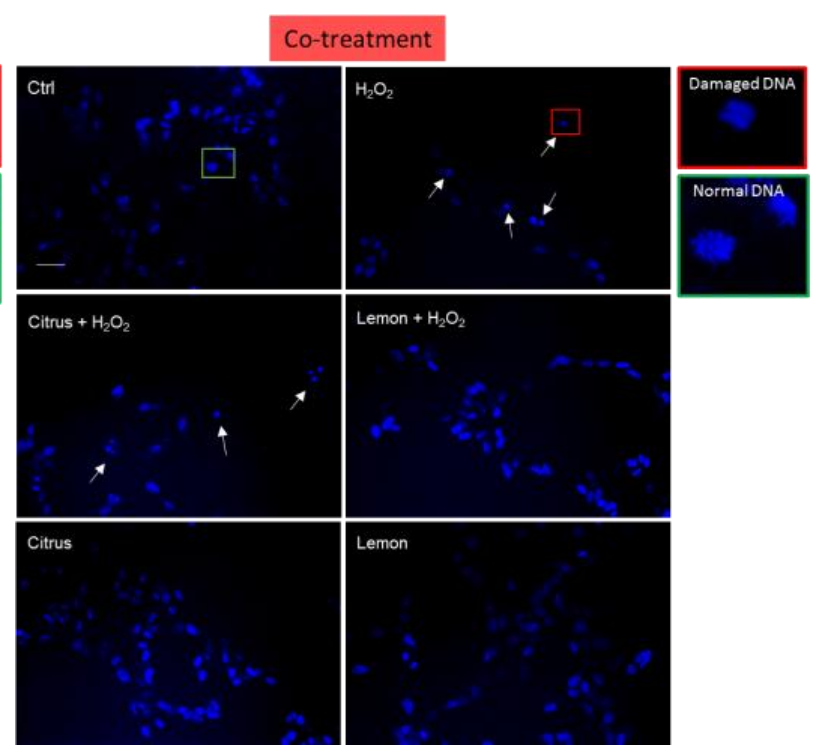

(b)

Figure A1. Effects of commercial (citrus) and lemon IntegroPectin (lemon) pectins on DNA damage: microscopy inspection for (a) pretreatment, and (b) co-treatment images of untreated cells (Ctrl) or treated with pectins or with $\mathrm{H}_{2} \mathrm{O}_{2}$ alone, or in combination with pectins. Bar: $100 \mu \mathrm{m}$. The square of the enlargements highlights the normal end of the damaged DNA.

\section{References}

1. Zaitseva, O.; Khudyakov, A.; Sergushkina, M.; Solomina, O.; Polezhaeva, T. Pectins as a universal medicine. Fitoterapia 2020, 146, 104676. [CrossRef]

2. Ciriminna, R.; Chavarría-Hernández, N.; Hernández, A.R.; Pagliaro, M. Pectin: A new perspective from the biorefinery standpoint. Biofuels Bioprod. Biorefin. 2015, 9, 368-377. [CrossRef]

3. Willats, W.G.T.; McCartney, L.; Mackie, W.; Knox, J.P. Pectin: Cell biology and prospects for functional analysis. Plant Mol. Biol. 2001, 47, 9-27. [CrossRef] [PubMed]

4. Ciriminna, R.; Fidalgo, A.; Meneguzzo, F.; Presentato, A.; Scurria, A.; Nuzzo, D.; Alduina, R.; Ilharco, L.M.; Pagliaro, M. Pectin: A long-neglected broad-spectrum antibacterial. ChemMedChem 2020, 15, 2228-2235. [CrossRef]

5. Liu, Y.; Dong, M.; Yang, Z.; Pan, S. Anti-diabetic effect of citrus pectin in diabetic rats and potential mechanism via PI3K/Akt signaling pathway. Int. J. Biol. Macromol. 2016, 89, 484-488. [CrossRef]

6. Wu, J.; Chen, M.; Shi, S.; Wang, H.; Li, N.; Su, J.; Liu, R.; Huang, Z.; Jin, H.; Ji, X.; et al. Hypoglycemic effect and mechanism of a pectic polysaccharide with hexenuronic acid from the fruits of Ficus pumila L. in C57BL/KsJ db/db mice. Carbohydr. Polym. 2017, 178, 209-220. [CrossRef]

7. Gunness, P.; Gidley, M.J. Mechanisms underlying the cholesterol-lowering properties of soluble dietary fibre polysaccharides. Food Funct. 2010, 1, 149-155. [CrossRef]

8. Feigin, V.L.; Nichols, E.; Alam, T.; Bannick, M.S.; Beghi, E.; Blake, N.; Culpepper, W.J.; Dorsey, E.R.; Elbaz, A.; Ellenbogen, R.G.; et al. Global, regional, and national burden of neurological disorders, 1990-2016: A systematic analysis for the Global Burden of Disease Study 2016. Lancet Neurol. 2019, 18, 459-480. [CrossRef]

9. Chin-Chan, M.; Navarro-Yepes, J.; Quintanilla-Vega, B. Environmental pollutants as risk factors for neurodegenerative disorders: Alzheimer and Parkinson diseases. Front. Cell Neurosci. 2015, 9, 124. [CrossRef]

10. Picone, P.; Di Carlo, M.; Nuzzo, D. Obesity and Alzheimer's disease: Molecular bases. Eur. J. Neurosci. 2020, 52, 3944-3950. [CrossRef] [PubMed]

11. Alfos, S. Chapter 13-Fish oil supplementation prevents age-related memory decline: Involvement of nuclear hormone receptors. In Omega-3 Fatty Acids in Brain and Neurological Health; Watson, R.R., De Meester, F., Eds.; Academic Press: Boston, MA, USA, 2014; pp. 147-161.

12. Nuzzo, D.; Picone, P. Potential neurological effects of severe COVID-19 infection. Neurosci. Res. 2020, 158, 1-5. [CrossRef] [PubMed]

13. Picone, P.; Nuzzo, D.; Caruana, L.; Scafidi, V.; Di Carlo, M. Mitochondrial dysfunction: Different routes to Alzheimer's disease therapy. Oxid. Med. Cell. Longev. 2014, 2014, 780179. [CrossRef] [PubMed]

14. Andersen, J.K. Oxidative stress in neurodegeneration: Cause or consequence? Nat. Med. 2004, 10, S18-S25. [CrossRef] [PubMed] 
15. Kim, G.H.; Kim, J.E.; Rhie, S.J.; Yoon, S. The role of oxidative stress in neurodegenerative diseases. Exp. Neurobiol. 2015, 24, 325-340. [CrossRef] [PubMed]

16. Fan, Y.; Sun, C.; Gao, X.; Wang, F.; Li, X.; Kassim, R.M.; Tai, G.; Zhou, Y. Neuroprotective effects of ginseng pectin through the activation of ERK/MAPK and Akt survival signaling pathways. Mol. Med. Rep. 2012, 5, 1185-1190. [CrossRef]

17. Leonoudakis, D.; Rane, A.; Angeli, S.; Lithgow, G.J.; Andersen, J.K.; Chinta, S.J. Anti-inflammatory and neuroprotective role of natural product securinine in activated glial cells: Implications for Parkinson's disease. Mediat. Inflamm. 2017, $2017,8302636$. [CrossRef] [PubMed]

18. Magalingam, K.B.; Radhakrishnan, A.K.; Haleagrahara, N. Protective mechanisms of flavonoids in Parkinson's disease. Oxid. Med. Cell. Longev. 2015, 2015, 314560. [CrossRef]

19. Bordoni, L.; Gabbianelli, R. Mitochondrial DNA and neurodegeneration: Any role for dietary antioxidants? Antioxidants 2020, 9 , 764. [CrossRef]

20. Mahalakshmi, B.; Maurya, N.; Lee, S.D.; Bharath Kumar, V. Possible neuroprotective mechanisms of physical exercise in neurodegeneration. Int. J. Mol. Sci. 2020, 21, 5895. [CrossRef]

21. Dhalaria, R.; Verma, R.; Kumar, D.; Puri, S.; Tapwal, A.; Kumar, V.; Nepovimova, E.; Kuca, K. Bioactive compounds of edible fruits with their anti-aging properties: A comprehensive review to prolong human life. Antioxidants 2020, 9, 1123. [CrossRef] [PubMed]

22. Meneguzzo, F.; Brunetti, C.; Fidalgo, A.; Ciriminna, R.; Delisi, R.; Albanese, L.; Zabini, F.; Gori, A.; dos Santos Nascimento, L.B.; De Carlo, A.; et al. Real-scale integral valorization of waste orange peel via hydrodynamic cavitation. Processes $2019,7,581$. [CrossRef]

23. Presentato, A.; Piacenza, E.; Scurria, A.; Albanese, L.; Zabini, F.; Meneguzzo, F.; Nuzzo, D.; Pagliaro, M.; Martino, D.C.; Alduina, R.; et al. A new water-soluble bactericidal agent for the treatment of infections caused by Gram-positive and Gram-negative bacterial strains. Antibiotics 2020, 9, 586. [CrossRef]

24. Nuzzo, D.; Cristaldi, L.; Sciortino, M.; Albanese, L.; Scurria, A.; Zabini, F.; Lino, C.; Pagliaro, M.; Meneguzzo, F.; Di Carlo, M.; et al. Exceptional antioxidant, non-cytotoxic activity of integral lemon pectin from hydrodynamic cavitation. ChemistrySelect 2020, 5, 5066-5071. [CrossRef]

25. Miyazono, Y.; Hirashima, S.; Ishihara, N.; Kusukawa, J.; Nakamura, K.I.; Ohta, K. Uncoupled mitochondria quickly shorten along their long axis to form indented spheroids, instead of rings, in a fission-independent manner. Sci. Rep. 2018, 8, 350. [CrossRef] [PubMed]

26. Chapa-Dubocq, X.; Makarov, V.; Javadov, S. Simple kinetic model of mitochondrial swelling in cardiac cells. J. Cell. Physiol. 2018, 233, 5310-5321. [CrossRef]

27. Kovalevich, J.; Langford, D. Considerations for the use of SH-SY5Y neuroblastoma cells in neurobiology. Methods Mol. Biol. 2013, 1078, 9-21. [CrossRef] [PubMed]

28. Van Meerloo, J.; Kaspers, G.J.; Cloos, J. Cell sensitivity assays: The MTT assay. Methods Mol. Biol 2011, 731, 237-245. [CrossRef] [PubMed]

29. Ly, J.D.; Grubb, D.R.; Lawen, A. The mitochondrial membrane potential $(\Delta \psi \mathrm{m})$ in apoptosis; an update. Apoptosis 2003, 8 , 115-128. [CrossRef]

30. Perelman, A.; Wachtel, C.; Cohen, M.; Haupt, S.; Shapiro, H.; Tzur, A. JC-1: Alternative excitation wavelengths facilitate mitochondrial membrane potential cytometry. Cell Death Dis. 2012, 3, e430. [CrossRef] [PubMed]

31. Baloyannis, S.J. Mitochondrial alterations in Alzheimer's disease. J. Alzheimers Dis. 2006, 9, 119-126. [CrossRef]

32. Vila, M.; Ramonet, D.; Perier, C. Mitochondrial alterations in Parkinson's disease: New clues. J. Neurochem. 2008, 107, 317-328. [CrossRef]

33. Chung, M.J.; Suh, Y.L. Ultrastructural changes of mitochondria in the skeletal muscle of patients with amyotrophic lateral sclerosis. Ultrastruct. Pathol. 2002, 26, 3-7. [CrossRef]

34. Filippov, M.P. Practical infrared spectroscopy of pectic substances. Food Hydrocoll. 1992, 6, 115-142. [CrossRef]

35. Coenen, G.J.; Bakx, E.J.; Verhoef, R.P.; Schols, H.A.; Voragen, A.G.J. Identification of the connecting linkage between homo- or xylogalacturonan and rhamnogalacturonan type I. Carbohydr. Polym. 2007, 70, 224-235. [CrossRef]

36. Morris, G.A.; Foster, T.J.; Harding, S.E. Further observations on the size, shape, and hydration of casein micelles from novel analytical ultracentrifuge and capillary viscometry approaches. Biomacromolecules 2000, 1, 764-767. [CrossRef]

37. Ciriminna, R.; Fidalgo, A.; Delisi, R.; Carnaroglio, D.; Grillo, G.; Cravotto, G.; Tamburino, A.; Ilharco, L.M.; Pagliaro, M. Highquality essential oils extracted by an eco-friendly process from different citrus fruits and fruit regions. ACS Sustain. Chem. Eng. 2017, 5, 5578-5587. [CrossRef]

38. Mohnen, D. Pectin structure and biosynthesis. Curr. Opin. Plant Biol. 2008, 11, 266-277. [CrossRef] [PubMed]

39. Kaya, M.; Sousa, A.G.; Crepeau, M.J.; Sorensen, S.O.; Ralet, M.C. Characterization of citrus pectin samples extracted under different conditions: Influence of acid type and $\mathrm{pH}$ of extraction. Ann. Bot. 2014, 114, 1319-1326. [CrossRef]

40. Scurria, A.; Sciortino, M.; Presentato, A.; Lino, C.; Piacenza, E.; Albanese, L.; Zabini, F.; Meneguzzo, F.; Nuzzo, D.; Pagliaro, M.; et al. Volatile compounds of lemon and grapefruit integropectin. Molecules 2021, 26, 51. [CrossRef]

41. Ciriminna, R.; Fidalgo, A.; Delisi, R.; Ilharco, L.; Pagliaro, M. Pectin production and global market. Agro Food Ind. Hi-Tech 2016, 27, 17-20.

42. Moghimi, M.; Parvardeh, S.; Zanjani, T.M.; Ghafghazi, S. Protective effect of alpha-terpineol against impairment of hippocampal synaptic plasticity and spatial memory following transient cerebral ischemia in rats. Iran. J. Basic Med. Sci. 2016, 19, 960-969. 
43. Burcul, F.; Blazevic, I.; Radan, M.; Politeo, O. Terpenes, phenylpropanoids, sulfur and other essential oil constituents as inhibitors of cholinesterases. Curr. Med. Chem. 2020, 27, 4297-4343. [CrossRef]

44. Vieira, G.; Cavalli, J.; Goncalves, E.C.D.; Braga, S.F.P.; Ferreira, R.S.; Santos, A.R.S.; Cola, M.; Raposo, N.R.B.; Capasso, R.; Dutra, R.C. Antidepressant-like effect of terpineol in an inflammatory model of depression: Involvement of the cannabinoid system and D2 dopamine receptor. Biomolecules 2020, 10, 792. [CrossRef]

45. Gattuso, G.; Barreca, D.; Gargiulli, C.; Leuzzi, U.; Caristi, C. Flavonoid composition of citrus juices. Molecules 2007, 12, 1641-1673. [CrossRef] [PubMed]

46. Hajialyani, M.; Hosein Farzaei, M.; Echeverria, J.; Nabavi, S.M.; Uriarte, E.; Sobarzo-Sanchez, E. Hesperidin as a neuroprotective agent: A review of animal and clinical evidence. Molecules 2019, 24, 648. [CrossRef]

47. Karim, N.; Shishir, M.R.I.; Gowd, V.; Chen, W. Hesperidin-an emerging bioactive compound against metabolic diseases and its potential biosynthesis pathway in microorganism. Food Rev. Int. 2021, 1-23. [CrossRef]

48. Ferreira, P.S.; Spolidorio, L.C.; Manthey, J.A.; Cesar, T.B. Citrus flavanones prevent systemic inflammation and ameliorate oxidative stress in C57BL/6J mice fed high-fat diet. Food Funct. 2016, 7, 2675-2681. [CrossRef] [PubMed]

49. Ribeiro, C.B.; Ramos, F.M.; Manthey, J.A.; Cesar, T.B. Effectiveness of Eriomin ${ }^{\circledR}$ in managing hyperglycemia and reversal of prediabetes condition: A double-blind, randomized, controlled study. Phytother. Res. 2019, 33, 1921-1933. [CrossRef] [PubMed]

50. Hu, S.; Kuwabara, R.; Beukema, M.; Ferrari, M.; de Haan, B.J.; Walvoort, M.T.C.; de Vos, P.; Smink, A.M. Low methyl-esterified pectin protects pancreatic beta-cells against diabetes-induced oxidative and inflammatory stress via galectin-3. Carbohydr. Polym. 2020, 249, 116863. [CrossRef] [PubMed]

51. Siew, J.J.; Chen, H.M.; Chen, H.Y.; Chen, H.L.; Chen, C.M.; Soong, B.W.; Wu, Y.R.; Chang, C.P.; Chan, Y.C.; Lin, C.H.; et al. Galectin-3 is required for the microglia-mediated brain inflammation in a model of Huntington's disease. Nat. Commun. 2019, 10, 3473. [CrossRef]

52. Zhang, T.; Zheng, Y.; Zhao, D.; Yan, J.; Sun, C.; Zhou, Y.; Tai, G. Multiple approaches to assess pectin binding to galectin-3. Int. J. Biol. Macromol. 2016, 91, 994-1001. [CrossRef]

53. Wang, W.; Wu, X.; Chantapakul, T.; Wang, D.; Zhang, S.; Ma, X.; Ding, T.; Ye, X.; Liu, D. Acoustic cavitation assisted extraction of pectin from waste grapefruit peels: A green two-stage approach and its general mechanism. Food Res. Int. 2017, 102, 101-110. [CrossRef] [PubMed]

54. Ciriminna, R.; Fidalgo, A.; Delisi, R.; Tamburino, A.; Carnaroglio, D.; Cravotto, G.; Ilharco, L.M.; Pagliaro, M. Controlling the degree of esterification of citrus pectin for demanding applications by selection of the source. ACS Omega 2017, 2, 7991-7995. [CrossRef]

55. Nuzzo, D.; Galizzi, G.; Amato, A.; Terzo, S.; Picone, P.; Cristaldi, L.; Mulè, F.; Di Carlo, M. Regular intake of pistachio mitigates the deleterious effects of a high fat-diet in the brain of obese mice. Antioxidants 2020, 9, 317. [CrossRef]

56. Nuzzo, D.; Contardi, M.; Kossyvaki, D.; Picone, P.; Cristaldi, L.; Galizzi, G.; Bosco, G.; Scoglio, S.; Athanassiou, A.; Di Carlo, M. Heat-resistant aphanizomenon flos-aquae (AFA) extract $\left(\mathrm{Klamin}^{\circledR}\right)$ as a functional ingredient in food strategy for prevention of oxidative stress. Oxid. Med. Cell. Longev. 2019, 9481390. [CrossRef] [PubMed]

57. Nuzzo, D.; Presti, G.; Picone, P.; Galizzi, G.; Gulotta, E.; Giuliano, S.; Mannino, C.; Gambino, V.; Scoglio, S.; Di Carlo, M. Effects of the aphanizomenon flos-aquae extract $\left(\mathrm{Klamin}^{\circledR}\right)$ on a neurodegeneration cellular model. Oxid. Med. Cell. Longev. 2018, 9089016. [CrossRef] [PubMed]

58. Nuzzo, D.; Amato, A.; Picone, P.; Terzo, S.; Galizzi, G.; Bonina, F.P.; Mulè, F.; Di Carlo, M. A natural dietary supplement with a combination of nutrients prevents neurodegeneration induced by a high fat diet in mice. Nutrients 2018, 10, 1130. [CrossRef] [PubMed]

59. Scurria, A.; Sciortino, M.; Albanese, L.; Nuzzo, D.; Zabini, F.; Meneguzzo, F.; Alduina, R.V.; Presentato, A.; Pagliaro, M.; Avellone, G.; et al. Flavonoids in Lemon and Grapefruit IntegroPectin. Preprints 2021, 2021020620. [CrossRef] 